COVID-19 and adherence to the regulations

This manuscript has been published in Health Psychology Bulletin and is available at http://doi.org/10.5334/hpb.32

\title{
University Students' Adherence to the COVID-19-guidelines: A Qualitative Study on Facilitators and Barriers
}

Tugce Varol*, Department of Work and Social Psychology, Maastricht University, The Netherlands

Francine Schneider, Department of Health Promotion, CAPHRI, Maastricht University, The Netherlands

Ilse Mesters, Department of Epidemiology, CAPHRI, Maastricht University, The Netherlands

Rik Crutzen, Department of Health Promotion, CAPHRI, Maastricht University, The Netherlands

Robert A.C. Ruiter, Department of Work and Social Psychology, Maastricht University, The Netherlands

Gerjo Kok, Department of Work and Social Psychology, Maastricht University, The Netherlands

Gill ten Hoor, Department of Work and Social Psychology, Maastricht University, The Netherlands

*Corresponding author: Tugce Varol, Dept. Work \& Social Psychology, Maastricht University, P.O. Box 616, 6200 MD Maastricht, The Netherlands

t.varol@maasrichtuniversity.nl 
COVID-19 and adherence to the regulations

\begin{abstract}
Objective. This study aims to explore students' adherence and reasons behind the (non)adherence to the COVID-19-regulations within a university setting.

Methods. A total of 33 students participated in on-site and online focus group interviews $(k=8)$.

Discussed topics included the general COVID-19-guidelines of the university, including keeping $\geq 1.5$ $\mathrm{m}$ distance, staying at home and getting tested when having symptoms, and wearing facemasks.

Additionally, education and psychosocial wellbeing in the times of COVID-19 were discussed. We also conducted online interviews with stewards ( 2 focus group interviews and 1 individual interview) and security/crowd control officials (1 focus group interview) to learn more about students' (non)adherence behaviors.
\end{abstract}

Results. The findings of this study show that the interviewed students were willing to adhere to the guidelines within the university buildings. They mentioned several facilitators (e.g., the infrastructure of the buildings and staff) and barriers (e.g., being together with friends and difficulties with telling others to follow the regulations) for their compliance behaviors. Some students also stated that they are not afraid of COVID-19 because they are young, while others adhered to the regulations to protect vulnerable people. Focus group interviews with stewards/security did not add anything new to the findings.

Conclusion. To create a safe environment within the university and alleviate the spread of the virus, future interventions require targeting the determinants of students' non-adherence behaviors, such as lower risk perception (e.g., being young and no perceived threat/low vulnerability) and lower selfefficacy (e.g., for keeping distance, to determine symptoms for testing/isolating and to correct others).

Key words: COVID-19, students, beliefs, guidelines, adherence, behavior change 
COVID-19 and adherence to the regulations

\section{Introduction}

The novel COVID-19 disease rapidly spread worldwide and was declared a pandemic by the World Health Organization (WHO, 2020a). Up till the moment that there is an effective and widely used medication and/or vaccine, health professionals recommend preventive behavioral measures to reduce the spread of the virus, such as hand hygiene, physical distancing, getting tested and quarantine, and wearing facemasks (Adhikari et al., 2020; Singhal, 2020; WHO, 2020b).

The first COVID-19 case of the Netherlands was confirmed on February 27, 2020 (RIVM, 2020). Since then, the number of cases drastically increased, and in the Netherlands the government announced the first intelligent lockdown on March 15, 2020, including closures of cafes, restaurants, bars, and schools (Rijksoverheid, 2020a). Intelligent lockdown refers to the combination of all measures to control the spread of the virus and minimize the effect of COVID-19 pandemic on economy and wellbeing by giving people advise and putting the emphasis on individual responsibility (Yerkes et al., 2020). Early June, when the reproduction number $\left(\mathrm{R}_{0}\right)$ returned below 1 , measures were somewhat relaxed and facilities in the Netherlands reopened again, but in such a way that people were able to follow the >1.5-metre physical distancing rule (Rijksoverheid, 2020b). At the time of writing this paper, the second wave of COVID-19 had been observed across Europe (including the Netherlands) and a full lockdown with additional restrictive measures was implemented on December $16,2020$.

Education programs from primary to tertiary level have also been impacted by COVID-19 (Sahu, 2020; Toquero, 2020), and schools and universities are trying to find ways to deliver educational activities without any postponement. Maastricht University (approximately 19,000 students, 54\% of whom are foreign: maastrichtuniversity.nl/about-um/organisation/facts-figures), where this study took place, adopted a hybrid education system, which allows online learning alongside in-person learning. The University Board applied the regulations of the National Institute for Public Health and the Environment (RIVM) in all educational facilities: keeping $\geq 1.5 \mathrm{~m}$-distance, washing or disinfecting hands, staying at home or getting tested when having complaints, and wearing 
COVID-19 and adherence to the regulations

facemasks (implemented from October 26, 2020). Besides, surveillance was established by corona stewards/security enforcing the COVID-19 rules on-site.

In an educational environment, preventing the spread of the virus also depends on the compliance behaviors of students with the preventive measures. As a first step in the development of an intervention to promote a safe environment for students by increasing adherence to the measures, applying the Intervention Mapping (IM) approach (Bartholomew-Eldredge et al., 2016; Fernandez et al., 2019), we conducted a needs assessment to gather information about the determinants and underlying beliefs behind the students' risk and preventive behaviors. In this study, we aimed to learn: a) students' adherence to the guidelines; and b) reasons behind students' (non)adherence to the guidelines, applying a qualitative approach. Based on the outcomes of this study, we will be able to identify the determinants and underlying beliefs behind students' (non)adherence behavior, which are the key elements of changing a behavior, moreover, to inform a quantitative survey to tailor the questionnaire based on the students' beliefs. The most relevant beliefs will serve as change objectives for a future intervention to promote (better) compliance with the preventive measures.

\section{Methods}

\section{Participants and recruitment}

After receiving approval by the Ethics Review Committee Psychology and Neuroscience, Maastricht University, students were invited to the study through the university's communication channels (e.g., newsletter, pop-up in the online learning management system (CANVAS) and student email), which included a recruitment paragraph with a registration link (aanmelder.nl/um-covid-19: an event page created for this study). The ideal number of participants for a focus group is between 5 to 8 (e.g., Bloor, 2001; Krueger \& Casey, 2014). Therefore, of the 118 students who registered for the study, 48 students were selected for 4 on-site (with 7 students for each) and 4 online (with 5 students for each) focus group interviews, as not all students might feel comfortable to join in on-site interviews. We selected students based on having a similar number of representatives from each of six faculties of Maastricht University, which also means they receive education in different buildings. The students, 
COVID-19 and adherence to the regulations

who were not selected for the focus group interviews, received a rejection email and were asked the reasons to follow and not to follow the COVID-19-regulations of the university (Supplementary materials, see Appendix 1). All students who participated received a 10-euro worth incentive for their participation.

In order to get an outsider's perspective on students' adherence behavior, we also interviewed corona-stewards and security/crowd-control officials who were active in the university building and were trained to monitor the adherence of personnel and students to the guidelines of the university. Corona-stewards are either students or personnel. They wear an orange vest for identification and warn students and staff members if they spot guideline deviant behavior. Security/crowd-control officials are professionals hired by an outside agency. They are recognizable by their uniform and enforce students to follow the $1.5 \mathrm{~m}$ distancing guideline when large groups entered or left a lecture hall. Interviewees were recruited through their employers. Ten stewards were invited to 2 online focus group interviews and 5 security people for a separate online interview. We selected stewards/security from all different faculties/buildings; starting vs. experienced; female and male; and of different ages.

In the end, a total of 33 (of 48) students ( 23 females and 10 males) participated in on-site and online focus group interviews (9 no-shows, and 6 last-minute cancellations because of mild cold symptoms). Twenty students attended on-site focus groups, and 13 students participated in online sessions, from six faculties: Health, Medicine and Life Sciences $(n=6)$; Psychology and Neuroscience $(n=3)$; Law $(n=5)$; Business and Economics $(n=5)$; Arts and Social Sciences $(n=4)$; Science and Engineering $(n=10)$. Five students, who sent additional responses via email, were from Psychology and Neuroscience $(n=1)$, Arts and Social Sciences $(n=1)$, Law $(n=2)$, and Science and Engineering $(n=1)$. Moreover, of 10 invited stewards, 1 male and 7 females (one of them was 73 years and for others, the age range was between 20 to 26 ) participated in the interviews (1 no-show and 1 lastminute cancellation). There were only 2 male security officials who could attend the study at the selected date/time. 
COVID-19 and adherence to the regulations

\section{Design and procedure}

Semi-structured focus group interviews were conducted with students. Each focus group interview was moderated by two researchers (facilitator and note-taker): the first two on-site and two online sessions were moderated by GtH and TV, the latter two on-site and two online sessions were conducted by FS and TV. On-site focus group interviews were held on September 9 and 10; online sessions were held via ZOOM on September 22 and 23, 2020. Focus group interviews lasted 1-1.5 hours and were conducted in English since Maastricht University has a large international staff and student population. All sessions were recorded with the consent of the participants prior to the start of the interviews. An information letter and consent form were provided before the focus group interviews, and signed consent forms were collected.

During the focus group interviews, an interview guide was used to structure the conversation. The university's corona protocol, i.e., keeping 1.5m-distance; staying at home/getting tested; and wearing facemasks (at that time not mandatory), was discussed to assess students' opinions/perceptions regarding these behaviors by comparing situations and behaviors inside and outside the university. Also, barriers and facilitators and communications about those regulations were addressed. After four on-site focus group interviews, the sessions were evaluated and, due to data saturation, the focus shifted to different aspects (e.g., stress, online \& on-site education, etc.) and details (e.g., do you feel comfortable asking people to keep their distance, are you afraid of getting COVID-19). In the online sessions, we also focused on the psychological and social aspects of the COVID-19 crisis and education in the times of COVID-19, as these topics were brought up by students during the on-site focus group interviews. The full interview guide can be found in the supplementary materials, Appendix 2.

Semi-structured focus group interviews with stewards took place on September 30, and October 1, and with security on October 5, 2020. We conducted two online focus group interviews with corona-stewards, moderated by FS and TV, one individual interview with one steward due to the language restrictions (in Dutch and moderated by GK) and one online focus group interview with security/crowd-control (in Dutch and moderated by IM). Focus group interviews with stewards were 
COVID-19 and adherence to the regulations

in English and lasted approximately 1.5 hours. Topics of discussions included their observations on the students' (non)compliance behaviors with UM COVID-protocol and their experiences with students.

\section{Data Analysis}

A combination of inductive and deductive thematic analysis was conducted (Braun \& Clarke, 2006; Fereday \& Muir-Cochrane, 2006). We firstly aimed to inductively identify various patterns in students' responses and later on, deductively validating these themes to the theories on health-behavior mentioned below (Vaismoradi et al., 2013).

\section{Inductive thematic analysis}

The focus group interviews with students were summarized in writing (TV, GtH, and FS) and quotes were transcribed verbatim (TV). After a thorough reading of the summaries, an inductive, data-driven analysis was independently conducted by two of the authors (GK \& TV) to generate the themes. The final themes were confirmed by consensus.

\section{Deductive thematic analysis}

Based on the following theories, themes were rechecked deductively for determinants and salient beliefs of the students regarding the regulations and behind their (non)adherence behavior. The final themes were confirmed by consensus. Behavior-oriented theories help intervention developers by explaining health-behavior (Bartholomew-Eldredge et al., 2016). Several theories guided the deductive thematic analysis: the Theory of Planned Behavior (TPB) (Ajzen, 2011; the Reasoned Action Approach, Fishbein \& Ajzen, 2010) postulate that people's behaviors are determined by their intentions to engage in that behavior, and intention is influenced by (1) attitude which is people's perception regarding the positive or negative consequences of performing a behavior; (2) perceived norm, which is people's perception of others' (dis)approval for performing a behavior, or people's perception of significant others' behavior; and (3) perceived behavioral control (or self-efficacy), which is people's perception of having required skills to perform a certain behavior. Those three determinants consist, in turn, of underlying beliefs that indicate the content of those skills/barriers, 
COVID-19 and adherence to the regulations

norms and consequences. Protection Motivation Theory (PMT) argues that one's response to a health threat is influenced by (1) threat appraisal, one's evaluations of severity of the threat and one's perceptions of susceptibility to the threat, and (2) coping appraisal, one's expectation of whether executing a response will lead a change (response efficacy) and one's perceived ability to execute this response successfully (self-efficacy). Threat and coping appraisals together lead to protection motivation, which is one's intention to execute the recommendations in response to a health threat (Milne et al., 2000; Norman et al., 2005; Peters et al., 2013; Rogers, 1975; Ruiter et al., 2014). Moreover, theories of automatic behavior and habits claim that these behaviors are external cue dependent and unconscious, so do not require the use of many cognitive resources (Verplanken, 2018).

\section{Data analysis of the focus group interviews with stewards/security}

The focus group interviews with stewards/security people were also summarized in writing by TV, FS, GK, and IM. As the main aim of these interviews was to gather more insights regarding students' (non)adherence to the university COVID-19-guidelines, we did not analyze these interviews in detail, but checked the texts for any additional findings.

\section{Results}

In this study, we aimed to explore students' adherence and reasons behind the (non)adherence to the COVID-19-regulations within a university. The final list of themes included: the general university COVID-19-guidelines, keeping distance, staying at home/getting tested, wearing a facemask, education and social aspects, and communications within the university (see Table 1 for themes).

\section{Opinions about the university's COVID-19 regulations in general}

Most students view the guidelines and infrastructure created in the university buildings as wellorganized (e.g., signs on the floor, the walking routes, $1.5 \mathrm{~m}$ apart tables and chairs, and the presence of stewards). Some students found it easy to follow the guidelines. However, other students stated that the information about the regulations that they received from the university is confusing and they have difficulties adhering to the guidelines. Also, students, especially first-years, indicated that due to the 
COVID-19 and adherence to the regulations

regulations, it is difficult to make new friends or meet with fellow students to socialize or study. For instance, one student stated:

"At the university, they made it very difficult to socialize there, that is, you scan in and go to your class and scan out as soon as it is done. So, there you don't really interact with anyone and your tutorials are really small groups." (student no. 22)

From a different perspective, another student argued:

"For me, it's nearly impossible to have a social life with taking the measurements into account because everyone I met before the corona crisis, I'm still meeting and it's just if someone feels cold or something, they let themselves tested and they say that to each other but when you meet other people, and they are your friends... Yeah. For me, it is impossible to keep the distance and I still have a social life and I want to continue having that. And it didn't really change during the crisis." (student no. 26)

When asked about their experiences within and outside of the university, students indicated that within the university, they more easily follow the guidelines, and feel safe. Whereas outside, they found it difficult to keep a distance from others, especially in the supermarket and city center. One student stated:

"When I am at the university - yes because it is quite empty and they are doing a really good job by making sure that there is only limited amount of people in the building, so it is really easy to stick to the guidelines, but in Maastricht overall, I would say it is not possible. You can be really careful, but as soon as you go to the supermarket, no one else cares." (student no.

In addition, some students mentioned that they are also not as careful outside as inside the university buildings regarding following the rules, e.g.:

"At least what I have experienced when we are at the university, we are a bit more careful because we know that we are in this institution and because we see the university staff that is 
COVID-19 and adherence to the regulations

also trying to remind us constantly to keep the distance, but then there are just so many opportunities outside the university to meet up with people. We are trying to keep a distance. Somehow it always ends up not happening at some point. We are either crossing each other or we are staying too close to each other." (student no. 28)

Additional beliefs arose from the discussions. First, some students mentioned that they are afraid of contracting COVID-19 and infecting other people, so they are adhering to the rules. On the other hand, some students stated that they are not afraid of getting COVID-19 because they are young. One student argued:

"Group mentality is that we accept the consequences. We know we are responsible for ourselves. We know we might get the virus." (student no. 4)

Second, regarding telling other people to follow the guidelines, some students deemed it challenging and instead would prefer someone with authority to do that. Also, one student mentioned:

"If people aren't going to respect that, that's their problem and you cannot really do policing to other people's lives." (student no. 22)

Third, students revealed that staff remind students to follow the regulations. Fourth, one student shared her concerns pertaining trusting other people's adherence behavior. Lastly, some students said that they worry about their future, such as finding an internship or a job, as there are less opportunities for placement and to meet staff and make a network.

\section{Keeping distance}

Even though students support the 1.5m-distance-from-others guideline, most students found it difficult with reasons as "with close friends; when you are new and seek new friends; outside of university buildings; in student houses or at home; while contacting with teacher or tutor; when there is no reminder; when you forget; when others don't keep their distance." For example, one student mentioned: 
COVID-19 and adherence to the regulations

"Like when you are inside the building, you have always these reminders of keeping your distance, but when you are back into the streets or just hang out with your friends, you don't have all these signs that remind you keep your distance. So automatically by instinct, you just go back together. It is also socially kind of hard to even with your friends keep one and a half meters... so yeah just by instinct you just go back to together." (student no. 31)

Some students stated that there is a lack of space in some university buildings to maintain a $1.5 \mathrm{~m}-$ distance. For instance, one student stated:

“There are certain things that individuals simply can't control. It is unlikely that all students and members of staff at the university keep a 1.5m-distance at all times: sometimes the rooms in which we have tutorials are very limited in terms of space for that to be possible, especially at the beginning and ending of sessions." (student no. 36)

In one of the focus group interviews, students discussed their negative experiences within the university library regarding adhering to the regulations. One student argued that at the library, especially during the opening and closing hours, there are too many people at the same spot and the stairs are too narrow. Moreover, students talked about their struggles to tell others to keep $1.5 \mathrm{~m}$ distance. Some students found it hard to stand up their own opinion and to warn their friends to keep distance.

Reasons behind students" keeping-distance behavior are "do not want to get sick; do not want to spread the virus to others; want to protect parents and grandparents; concerned for public health." One student stated:

"I like to keep the distance because I do not want to get Corona in the first place, but I am not worried about me too much because I am young and of good health. I like to keep the distance more because I want to protect my parents or grandparents, who are more vulnerable, from catching the virus." (student no. 38)

On the contrary, one of the most common reasons why students do not adhere to or having difficulties adhering to keeping $1.5 \mathrm{~m}$-distance regulation relates to the social aspect. Some students conveyed that 
COVID-19 and adherence to the regulations

they want to sit together with their friends, have drinks and go their friends' places, so to socialize; even though they normally try to keep distance, when they are together with their friends, distancing becomes impossible to adhere to.

\section{Getting tested/ staying at home}

There was a wide range of beliefs for (non)adherence to the regulation of staying at home and getting tested when having symptoms. Some students thought that getting tested is easy while some others found it difficult. The reasons behind not getting tested/staying at home included "financial reasons; scared of missing lectures; scared of testing positive." On the other hand, the reasons for getting tested/staying at home were "responsibility towards others; taking care of oneself." For instance, in case of having symptoms, one student stated:

"If I would not feel well, I would stay home immediately and get tested. The most important reason is not to form a risk for my family and other people. I actually had a cold in April for about a week and during that time and a period after, I didn't go anywhere and did my grocery shopping online.” (student no. 35)

Students mentioned that they struggle to detect or differentiate the symptoms of COVID-19 from other diseases or a cold. If they have sneeze or cough that might as well be an allergy, or in case they have headache, understanding whether it is COVID-19 or not is difficult. However, some students thought that in every case, they should stay at home even if they have mild symptoms:

"There is lack of responsibility because if you are feeling sick, you shouldn't go to school, but on the other part, I get that it is also difficult to relate every symptom to coronavirus. But of course, if I feel like that I wouldn't go to school." (student no. 23)

\section{Wearing a facemask}

At the time of focus group interviews (September 2020), facemasks were not compulsory (since October 2020, students and staff are obliged to wear facemasks inside the university, when walking or standing). Although students mostly argued that facemasks are important, they were content to have a 
COVID-19 and adherence to the regulations

choice to wear masks or not. On the other hand, if it would become mandatory at the university, they would not see that as a problem. Some students mentioned that they are wearing facemasks at the university and/or while doing grocery shopping. Also, some students stated that when other people wear facemasks, they feel safer. There was a discussion regarding the impact of wearing facemasks on the adherence to the other measures. Some students conveyed that it enhances distancing behavior because when they see people who are wearing facemasks, that reminds them to keep distance. Nevertheless, others thought that it negatively affects distancing behavior as people come closer because they think that wearing a facemask protects them getting infected.

Table 1. Determinants and underlying beliefs of students' adherence to the regulations

\begin{tabular}{|c|c|c|}
\hline Themes & Inductive & Deductive \\
\hline \multirow{4}{*}{$\begin{array}{l}\text { Opinions about the } \\
\text { university's COVID- } \\
19 \text { regulations in } \\
\text { general }\end{array}$} & $\begin{array}{l}\text { not afraid of contracting COVID-19 } \\
\text { feeling safe inside the university } \\
\text { susceptible to contract COVID-19 } \\
\text { the physical and social consequences of contracting } \\
\text { COVID-19 }\end{array}$ & Risk Perception Belief \\
\hline & $\begin{array}{l}\text { makes it difficult to meet and connect with other } \\
\text { students } \\
\text { well-organized } \\
\text { guidelines are irrelevant for our generation } \\
\text { worrying about my future } \\
\text { trust in other people's adherence behavior } \\
\text { telling people around me to adhere to the guidelines }\end{array}$ & Attitudinal Belief \\
\hline & staff members remind to follow the regulations & Normative Belief \\
\hline & $\begin{array}{l}\text { difficult to adhere to } \\
\text { information about the guidelines is confusing } \\
\text { outside the university buildings }\end{array}$ & Control Belief \\
\hline \multirow{4}{*}{ Keeping distance } & $\begin{array}{l}\text { do not want to get sick } \\
\text { want to protect parents and grandparents (vulnerable) }\end{array}$ & Risk Perception Belief \\
\hline & $\begin{array}{l}\text { do not want to spread the virus to others } \\
\text { concerned for public health } \\
\text { meeting social contacts } \\
\text { while contacting with teacher or tutor } \\
\text { when you are new and seek new friends }\end{array}$ & Attitudinal Belief \\
\hline & $\begin{array}{l}\text { with close friends } \\
\text { in student houses or at home } \\
\text { difficult to tell other people to keep } 1.5 \mathrm{~m} \text { distance } \\
\text { from me } \\
\text { not enough space in the buildings to keep distance } \\
\text { facilities within the university } \\
\text { outside the university buildings }\end{array}$ & Control Belief \\
\hline & when there is no reminder & abit \\
\hline
\end{tabular}


COVID-19 and adherence to the regulations

\begin{tabular}{cll} 
& when you forget & \\
\hline \multirow{3}{*}{ Getting tested/ } & $\begin{array}{l}\text { scared of missing lectures } \\
\text { taking care of oneself } \\
\text { responsibility towards others } \\
\text { staying at home }\end{array}$ & Attitudinal Belief \\
& scared of testing positive & \\
\cline { 2 - 3 } & $\begin{array}{l}\text { financial reasons } \\
\text { difficulty to detect or differentiate the symptoms of } \\
\text { COVID-19 from other diseases }\end{array}$ & Control Belief \\
\hline \multirow{3}{*}{ Wearing a face mask } & $\begin{array}{l}\text { while wearing my facemask, keeping 1.5m distance } \\
\text { is less needed/relevant }\end{array}$ & Risk Perception Belief \\
\cline { 2 - 3 } & feeling more safe while wearing a facemask & Attitudinal Belief \\
\hline
\end{tabular}

\section{Social and psychological aspects and education during COVID-19}

Due to the online lectures and COVID-19 measures, almost all students stated that they find it difficult to make new friends online and meet with people at the university. They claimed that they had a chance to socialize with their potential friends before and after the lectures or during the breaks before COVID-19. However, now, since teaching is mostly online or because of the regulations at the university, they could not meet with fellow students. Therefore, due to the lack of social support, they felt that they experienced more stress.

According to students, the transition from onsite to hybrid/online education was very prompt, and it worked well, albeit with some small problems. All students preferred on-campus education as opposed to online lectures. They found the online education environment more challenging, stressful, and tiring. Some students stated that they are required to spend long hours in front of a screen during the online lectures, which might be more difficult for students who have concentration problems. Also, they conveyed that some students might not have a suitable learning environment at home or in student houses. Furthermore, during the online lectures and tutorials, they found it hard to engage and ask questions.

\section{Communications within the university}

Students argued that updates by email are helpful yet too long, so they generally skip them without reading. They would prefer short and clear emails and transparent communication. They stated that they would like the news communicated very fast, as the press conferences are in Dutch and 
COVID-19 and adherence to the regulations

international students need translations to be informed about the new regulations. Most students found the guidelines and visuals within the university buildings clear and informative.

\section{Additional information from stewards and crowd control}

Stewards conveyed that students mostly give a positive response when they approach them to keep their distance. They observed that in some locations (e.g., because of the infrastructure) and situations (e.g., before and after the lectures), compliance decreases. They mentioned that students are trying to stick to the rules, but sometimes they forget to do so (e.g., disinfecting tables after the lectures or using hand sanitizer upon entering the buildings). One interesting finding was that stewards/security stated that in comparison with students, staff members are less compliant with COVID-19 measures of the university and less willing to adapt their behaviors.

\section{Discussion}

In this project, our final goal is to create an intervention to minimize the spread of the coronavirus by enhancing students' compliance with COVID-19-regulations of the university. The development of an effective behavior change intervention requires an understanding of the target groups' behavior and determinants of those behaviors (Bartholomew-Eldredge et al., 2016; Kok et al., 2016). Therefore, we examined the (non)adherence behaviors of students to the regulations and the determinants behind those behaviors.

The findings of our study revealed that most of the participants have positive attitudes towards the measures. In addition to expressing their willingness to adhere to the COVID-19-guidelines, they also mentioned facilitators and barriers for their (non)compliance. They thought that the university's COVID-19-guidelines and the established infrastructure mostly serve as a buffer against infection. However, some students also stated that they have difficulties in keeping distance where there is not enough space (e.g., check-in/out and stairs at the library). In addition, students mentioned that sometimes keeping distance is not up to them because others do not keep their distance. In such situations, they feel uncomfortable telling others to keep $1.5 \mathrm{~m}$-distance and prefer tutors/teachers or stewards to keep order. Also, almost all students mentioned the social aspect of the guidelines. Even 
COVID-19 and adherence to the regulations

though they want to comply, they also stated that it is difficult to make new friends or meaningful contacts under these circumstances. When they meet with their friends, it becomes impossible to adhere to the guidelines because either they do not care or do not pay attention to keeping distance. Barrett and Cheung (2020) explored the determinants of distancing and hand hygiene behaviors among UK university students and found that low self-efficacy significantly negatively impacts students' social distancing behavior. Moreover, Beeckman et al. (2020) also demonstrated that among the adult population self-efficacy is one of the determinants of physical distancing behavior. People who adhere to the coronavirus measures reported that they are confident about their skills to comply with the rules. In line with these findings, as students in our study reported that they are having difficulties with keeping distance when together with friends or telling others to keep their distance, being low in self-efficacy might act as a barrier for students' adherence to the COVID-19-regulations.

Concerning risk perception beliefs, some students reported that they are not afraid of contracting coronavirus because they are young, so that the consequences might be minimum for themselves. However, some of them added that they are afraid of infecting others with coronavirus. De Bruin and Bennett (2020) found that people who perceive higher risks of COVID-19 infection, show more compliance with preventive behaviors such as physical distancing. Hence, risk perception can be one of the factors that impact students' adherence to the regulations. Also, as studies revealed that perceived norm is an important determinant of compliance with the preventive behaviors (Folmer et al., 2020; Hagger et al., 2020), students' perception of their friends' or tutors/teachers' behavior might be another factor that has an effect on students' preventive behaviors. Moreover, students also stated that sometimes they simply forget to keep $1.5 \mathrm{~m}$-distance from others and fall back into routines, which is in line with the findings of Hagger et al. (2020).

The limitations of this study include that since the measures constantly change due to the circumstances, people's compliance behavior might also alter. For instance, at the time of the focus group interviews, facemasks were not mandatory. Currently, they are obliged in public places and in shops and buildings where people come together. However, although new developments happen(ed) every day, the nature of the specific regulations in this study (i.e., distancing, testing and isolating) 
COVID-19 and adherence to the regulations

remained unchanged throughout the period of data collection. Another limitation is that the results were based on self-reports of a limited number of students, but steward/security data confirmed findings. On the other hand, although we did not aim to sample to saturation, the interviews and observations produced little change to the codebook after the initial on-site focus group interviews.

\section{Conclusion}

The main findings of the interviews show that most students were in favor of the COVID-19regulations, if not for themselves than at least to protect the vulnerable. At the same time, they found adhering to these rules difficult in some situations. On the one hand, the infrastructure and university staff and surveillance personnel were deemed helpful for students' adherence to the guidelines. On the other hand, the factors that hinder adherence behaviors of students included the physical environment; the need to socialize; being low in self-efficacy to correct others; forgetting; no perceived threat, and/or low vulnerability such as being young. Based on the information gathered during the interviews, (low) self-efficacy and (low) risk perception might be the most relevant determinants behind the (non-)adherence behaviors of students. Also, perceived norms and habits might impact students' preventive behaviors. The information gathered in this study will inform the following quantitative survey study, as the next step to identify the most relevant determinants of students' (non)adherence behaviors to the guidelines, resulting in concrete ideas for an intervention to promote COVID-19-preventive behaviors. 
COVID-19 and adherence to the regulations

\section{Ethics and consent}

This study was approved by the Ethics Review Committee Psychology \& Neuroscience, Maastricht University, ref. 188_10_02_2018_S59. All participants consented to participate in the study.

\section{Competing interests}

The authors declare that they have no competing interests. 
COVID-19 and adherence to the regulations

\section{References}

Adhikari, S. P., Meng, S., Wu, Y. J., Mao, Y. P., Ye, R. X., Wang, Q. Z., ... \& Zhou, H. (2020). Epidemiology, causes, clinical manifestation and diagnosis, prevention and control of coronavirus disease (COVID-19) during the early outbreak period: a scoping review. Infectious diseases of poverty, 9(1), 1-12. https://doi.org/10.1186/s40249-020-00646-X

Ajzen, I. (2011). The theory of planned behavior: Reactions and reflections. Psychology \& Health, 26(9), 1113-1127. https://doi.org/10.1080/08870446.2011.613995

Barrett, C., \& Cheung, K. L. (2020). Knowledge, Socio-cognitive Perceptions and the Practice of Hand Hygiene and Social Distancing During the COVID-19 Pandemic: A Cross-sectional Study of UK University Students. https://doi.org/10.21203/rs.3.rs-60033/v1

Bartholomew-Eldredge, L. K., Markham, C. M., Ruiter, R. A., Fernández, M. E., Kok, G., \& Parcel, G. S. (2016). Planning health promotion programs: an intervention mapping approach. John Wiley \& Sons.

Beeckman, M., De Paepe, A., Van Alboom, M., Maes, S., Wauters, A., Baert, F., ... \& Poppe, L. (2020). Adherence to the Physical Distancing Measures during the COVID-19 Pandemic: A HAPA-Based Perspective. Applied Psychology: Health and Well-Being. https://doi.org/10.1111/aphw.12242

Bloor, M. (Ed.). (2001). Focus groups in social research. Sage.

Braun, V., \& Clarke, V. (2006). Using thematic analysis in psychology. Qualitative research in psychology, 3(2), 77-101.

De Bruin, W. B., \& Bennett, D. (2020). Relationships Between Initial COVID-19 Risk Perceptions and Protective Health Behaviors: A National Survey. American Journal of Preventive Medicine. https://doi.org/10.1016/j.amepre.2020.05.001 
COVID-19 and adherence to the regulations

Fereday, J., \& Muir-Cochrane, E. (2006). Demonstrating rigor using thematic analysis: A hybrid approach of inductive and deductive coding and theme development. International journal of qualitative methods, 5(1), 80-92. https://doi.org/10.1177\%2F160940690600500107

Fernandez, M. E., Ruiter, R. A., Markham, C. M., \& Kok, G. (2019). Theory-and evidence-based health promotion program planning: intervention mapping. Frontiers in public health, 7, 209. https://doi.org/10.3389/fpubh.2019.00209

Fishbein, M., \& Ajzen, I. (2010). Predicting and changing behavior: The reasoned action approach. New York: Taylor \& Francis Group.

Folmer, C. R., Kuiper, M., Olthuis, E., Kooistra, E. B., de Bruijn, A. L., Brownlee, M., ... \& van Rooij, B. (2020). Sustaining Compliance with Covid-19 Mitigation Measures? Understanding Distancing Behavior in the Netherlands during June 2020.

Hagger, M. S., Smith, S. R., Keech, J. J., Moyers, S. A., \& Hamilton, K. (2020). Predicting social distancing intention and behavior during the COVID-19 pandemic: An integrated social cognition model. Annals of Behavioral Medicine, 54(10), 713-727. https://doi.org/10.1093/abm/kaaa073

Kok, G., Gottlieb, N. H., Peters, G.-J. Y., Mullen, P. D., Parcel, G. S., Ruiter, R. A. C., Fernández, M. E., Markham, C., \& Bartholomew, L. K. (2016). A taxonomy of behavior change methods: An Intervention Mapping approach. Health Psychology Review, 10 (3), 297-312. https://doi.org/10.1080/17437199.2015.1077155

Krueger, R. A. \& Casey, M.A. (2014). Focus groups: A practical guide for applied research. Sage publications, Thousand Oaks, California, United States.

Milne, S., Sheeran, P., \& Orbell, S. (2000). Prediction and intervention in health-related behavior: A meta-analytic review of protection motivation theory. Journal of applied social psychology, 30(1), 106-143. https://doi.org/10.1111/j.1559-1816.2000.tb02308.x 
COVID-19 and adherence to the regulations

National Institute for Public Health and the Environment (RIVM). (2020). Patient with novel coronavirus COVID-19 in the Netherlands. (accessed November, 2020) https://www.rivm.nl/en/news/patient-with-novel-coronavirus-covid-19-in-netherlands

Norman, P., Boer, H., \& Seydel, E. R. (2005). Protection motivation theory. Predicting health behaviour, 81, 126.

Peters, G.J.Y., Ruiter, R.A.C., Kok, G. (2013). Threatening communication: a critical re-analysis and a revised meta-analytic test of fear appeal theory. Health Psychology Review,7:sup1, S8-S31. https://doi.org/10.1080/17437199.2012.703527

Rijksoverheid. (2020a). Aanvullende maatregelen onderwijs, horeca, sport.

https://www.rijksoverheid.nl/actueel/nieuws/2020/03/15/aanvullende-maatregelen-onderwijs-horeca$\underline{\text { sport }}$ (accessed November 2020)

Rijksoverheid. (2020b). Coronavirus dashboard. https://coronadashboard.government.n1/landelijk/reproductiegetal (accessed November 2020)

Rogers, R. W. (1975). A protection motivation theory of fear appeals and attitude change1. The journal of psychology, 91(1), 93-114. https://doi.org/10.1080/00223980.1975.9915803

Ruiter, R.A.C., Kessels, L.T.E., Peters, G-J, Y., \& Kok, G. (2014). Sixty years of fear appeal research: Current state of the evidence. International Journal of Psychology, 49, 63 -70. https://doi.org/10.1002/ijop.12042

Sahu, P. (2020). Closure of universities due to Coronavirus Disease 2019 (COVID-19): impact on education and mental health of students and academic staff. Cureus, 12(4). https://doi.org/10.7759/cureus.7541

Singhal, T. (2020). A review of coronavirus disease-2019 (COVID-19). The Indian Journal of Pediatrics, 1-6. https://doi.org/10.1007/s12098-020-03263-6 
COVID-19 and adherence to the regulations

Toquero, C. M. (2020). Challenges and Opportunities for Higher Education Amid the COVID-19 Pandemic: The Philippine Context. Pedagogical Research, 5(4). https://doi.org/10.29333/pr/7947

Vaismoradi, M., Turunen, H., \& Bondas, T. (2013). Content analysis and thematic analysis: Implications for conducting a qualitative descriptive study. Nursing \& health sciences, 15(3), 398-405. https://doi.org/10.1111/nhs. 12048

Verplanken B (Ed.) (2018). The psychology of habit: Theory, mechanisms, change, and contexts. Springer.

World Health Organization. (2020a). Coronavirus disease 2019 (COVID-19): situation report, 52. https://apps.who.int/iris/handle/10665/331476 (accessed November 2020)

World Health Organization. (2020b). Coronavirus disease 2019 (COVID-19): situation report, 72. https://apps.who.int/iris/bitstream/handle/10665/331685/nCoVsitrep01Apr2020-eng.pdf (accessed November 2020)

Yerkes, M. A., André, S. C., Besamusca, J. W., Kruyen, P. M., Remery, C. L., van der Zwan, R., ... \& Geurts, S. A. (2020). 'Intelligent' lockdown, intelligent effects? Results from a survey on gender (in) equality in paid work, the division of childcare and household work, and quality of life among parents in the Netherlands during the Covid-19 lockdown. PloS one, 15(11), e0242249. https://doi.org/10.1371/journal.pone.0242249 